[3] A. D. Buckingham, E. Lippert, and S. Bratos (eds.), Organic Liquids (J. Wiley \& Sons), 1978.

[4] J. Dupuy and A. J. Dianoux (eds.), Microscopic Structure and Dynamics of Liquids (Plenum Press), 1978.

[5] M. D. Martin, G. J. Martin, and J.-J. Delpuech, Practical NMR Spectroscopy (Heyden \& Sons Ltd.), 1980.

[6] F. X. Prielmeier, E. W. Lang, and H.-D. Lüdemann, Mol. Phys. 52, 1105 (1984).

[7] D. Chandler, Ann. Rev. Phys. Chem. 29, 441 (1978).

[8] H. J. V. Tyrrell and K. R. Harris, Diffusion in Liquids, p. 276, (Butterworth \& Co. Ltd.), 1984.

[9] B. J. Alder, D. M. Gass, and T. E. Wainwright, J. Chem. Phys. 53, 3813 (1970).

[10] D. Chandler, J. Chem. Phys. 62, 1358 (1975).

[11] O. Bozdag and E. U. Franck, private communication.

[12] TRC tables: Selected values of chemical compounds 1981.

[13] H. J. Böhm, C. Meissner, and R. Ahlrichs, Mol. Phys. 53, 651 (1984).

[14] H. W. Spieß, Rotation of Molecules and Nuclear Spin Relaxation in P. Diehl, E. Fluck, and R. Kosfeld (eds.), NMR-Basic Principles and Progress, Vol. 15 (Springer Verlag), 1982.

[15] P. K. Bhattacharyya and B. P. Dailey, J. Chem. Phys. 63, 1336 (1975).

[16] R. Ditchfield, Conference on Critical Evaluation of Chemical and Physical Structural Information, Dartmouth College, 1973.

[17] A. Gerschel, I. Dimicoli, J. Jaffre, and A. Rion, Mol. Phys. 32, 679 (1976)

[18] Lian-Pin Hwang and J. H. Freed, J. Chem. Phys. 63, 4017 (1975).

[19] C. A. Sholl, J. Phys. C 14, 447 (1981).

[20] J. F. Harmon, J. Magn. Reson. 31, 411 (1978).

[21] R. E. D. McClung, J. Chem. Phys. 73, 2435 (1980)

[22] P. S. Hubbard, Phys. Rev. A 9, 481 (1974).

[23] P. S. Hubbard, Phys. Rev. A 24, 645 (1981)

[24] S. C. Wofsy, J. S. Muenter, and W. Klemperer, J. Chem. Phys. 55,2014 (1971)

[25] F. C. DeLucia and J. W. Cederberg, J. Mol. Spectry. 40, 52 (1971).
[26] W. B. Moniz, W. A. Steele, and J. A. Dixon, J. Chem. Phys. 38,2418 (1963)

[27] R. E. D. McClung, Adv. Mol. Relax. Interact. Processes 10, 83 (1977).

[28] A. Gerschel, C. Brot, I. Dimicoli, and A. Rion, Mol. Phys. 33, 527 (1977).

[29] G. Lévi, J. P. Marsault, F. Marsault-Hérail, and R. E. D. McClung, J. Chem. Phys. 73, 2443 (1980).

[30] See R. M. Lynden-Bell, in [2], p. $501 \mathrm{ff}$.

[31] F. A. Andersen, B. Bak, and S. Brodersen, J. Chem. Phys. 24, 989 (1956).

[32] T. R. Krugh and R. A. Bernheim, J. Chem. Phys. 52, 4942 (1970).

[33] W. C. Malm, Dissertation, University of Missouri 1972.

[34] J. Jokisaari and Y. Hiltunen, J. Magn. Reson. 67, 319 (1986).

[35] S. G. Kukolich and C. D. Cogley, J. Chem. Phys. 76, 1685 (1982).

[36] J. Jokisaari and Y. Hiltunen, J. Magn. Reson. 60, 307 (1984).

[37] J. W. Emsley, J. C. Lindou, and J. Tabony, Mol. Phys. 26, 1499 (1973)

[38] J. L. Ragle, G. Minott, and M. Mokarram, J. Chem. Phys. 60,3184 (1974)

[39] R. V. Gregory, M. R. Asdjodi, H. G. Spencer, A. L. Beyerlein, and G. B. Savitsky, J. Chem. Phys. 81, 4790 (1984).

[40] J. DeZwaan, D. W. Hess, and Ch. S. Johnson, Jr., J. Chem. Phys. 63, 422 (1975)

[41] S. G. Kukolich, A. C. Nelson, and D. J. Ruben, J. Mol. Spectrosc. 40, 33 (1971).

[42] H. S. Sandhu, J. Magn. Reson. 34, 141 (1979).

[43] H. S. Sandhu, J. Magn. Reson. 26, 7 (1977).

[44] J. L. Ragle and K. L. Sherk, J. Chem. Phys. 50, 3553 (1969).

[45] H. S. Sandhu and H. Peemoeller, J. Magn. Reson. 21, 349 (1976).

[46] J. Gompf, H. Versmold, and H. Langer, Ber. Bunsenges. Phys. Chem. 86, 1114 (1982).

[47] J. Gompf and H. Versmold, Ber. Bunsenges. Phys. Chem. 88 , $733(1984)$

(Eingegangen am 19. März 1987, endgültige Fassung am 18. Mai 1987)
E 6467

\title{
High Pressure NMR Study of the Molecular Dynamics of Liquid Fluoroform and Deutero-Fluoroform
}

\author{
E. W. Lang, F. X. Prielmeier, H. Radkowitsch, and H.-D. Lüdemann
}

Institut für Biophysik und Physikalische Biochemie, Universität Regensburg, Postfach 397, D-8400 Regensburg

\section{Diffusion / High Pressure / Liquids / Spectroscopy, Nuclear Magnetic Resonance / Transport Properties}

The ${ }^{2} \mathrm{D}$-, ${ }^{1} \mathrm{H}$ - and ${ }^{19} \mathrm{~F}$-spin-lattice relaxation rates $R_{1}$ have been investigated in fluid fluoroform in the temperature range $150 \mathrm{~K} \leq T \leq$ $450 \mathrm{~K}$ and at pressures up to $p=200 \mathrm{MPa}$. Previous measurements of the self-diffusion coefficient $D$ have been supplemented to cover the same $p . T$-interval. Within the rough hard sphere (RHS) approximation a temperature independent RHS diameter $d$ and a strongly temperature dependent rotation-translation coupling $A_{\mathrm{RT}}$ are obtained. Both parameters are also compared with those obtained in a series of related halomethanes. The total ${ }^{2} \mathrm{D}-,{ }^{1} \mathrm{H}$ - and ${ }^{19} \mathrm{~F}$-relaxation rates in $\mathrm{CDF}_{3}$ and $\mathrm{CHF}_{3}$ are decomposed into their respective quadrupole, dipolar and spin-rotation contributions and orientational and spin-rotational correlation times are extracted from these rates. It is shown that they are in good agreement with the predictions of the Fokker-Planck-Langevin model. Inertial effects influence the molecular dynamics at high temperatures and low densities. The agreement of self-diffusion coefficients and orientational correlation times with MD-simulation data is very satisfactory.

\section{Introduction}

The molecular dynamics of liquid fluoroform have been studied in recent years by a variety of experimental techniques such as NMR, dielectric relaxation and absorption, Raman scattering, and IR-spectroscopy $[1-10]$. From the high frequency methods orientational correlation functions may be obtained over a limited time range and details of the short time dynamics of orientational fluctuations unravelled. NMR studies cannot yield such detailed information since in the short correlation time limit only the area of the relevant correlation function is determined and not its shape. However, if spin-rotation interactions dominate, 
the NMR method offers the unique possibility to obtain correlation times of angular velocity fluctuations. Hence dynamic parameters deduced from NMR-experiments include the self-diffusion coefficient $D$, the molecular orientation correlation time $\tau_{0,2}$ and the correlation time $\tau_{\omega,}$ of the molecular angular velocity. Together these parameters provide valuable insight into the state of molecular motion.

In the past liquid fluoroform $[1-3]$ and deuterofluoroform [4] have been investigated with relaxation rate and Overhauser effect measurements. The dominant interactions were found to be dipole-dipole and spin-rotation interactions in the former and quadrupole interactions in the latter. Since $\mathrm{CHF}_{3}$ is a symmetric-top molecule, although of almost spherical shape, in principle two orientational correlation times may be expected. However, a comparison of the experimental results obtained in $\mathrm{CHF}_{3}$ and $\mathrm{CDF}_{3}$ revealed that the orientational fluctuations are nearly isotropic [4]. Almost all investigations of fluoroform hitherto have been conducted under saturation vapor pressure. The present investigation is a study, by NMR methods, of $\mathrm{CHF}_{3}$ and $\mathrm{CDF}_{3}$ in the neat liquid phase over the temperature range $150 \mathrm{~K}$ to $450 \mathrm{~K}$ and a pressure range $0.1 \mathrm{MPa}$ to $200 \mathrm{MPa}$.

\section{Experimental}

Spin-lattice relaxation times were measured by the inversionrecovery method with alternating phase [11] on a Bruker MSL300 multipurpose solid-liquid NMR spectrometer operating at $300.13(\mathrm{MHz})$ for ${ }^{1} \mathrm{H}, 282.35(\mathrm{MHz})$ for ${ }^{19} \mathrm{~F}$ and $46.07(\mathrm{MHz})$ for ${ }^{2} \mathrm{H}$ and on a Varian $\mathrm{XL} 100$ high resolution spectrometer operating at $100.1(\mathrm{MHz})$ for ${ }^{1} \mathrm{H}, 94(\mathrm{MHz})$ for ${ }^{19} \mathrm{~F}$ and $15.35(\mathrm{MHz})$ for ${ }^{2} \mathrm{H}$. Selfdiffusion coefficients $D$ were determined on the MSL-300 spectrometer equipped with a Bruker gradient unit and home-built Helmholtz coils were used to apply pulsed field gradients. The experimental procedure and high-pressure equipment have been described elsewhere [12]. The relaxation times and the self-diffusion coefficients are judged reliable to $\pm 5 \%$.

The pressure was measured with a Heise bourdon gauge (Heise, Connecticut, USA) with a precision of $\pm 0.6(\mathrm{MPa})$. The temperatures were measured with a $0.5(\mathrm{~mm})$ Chromel-Alumel thermocouple (Philips, Kassel, FRG) and are considered reliable to $\pm 1(\mathrm{~K})$.

\section{Substances}

Fluoroform $(98 \%)$ was purchased from Baker Chemikalien (Groß-Gerau, FRG) and deuterated fluoroform $\left(98 \%{ }^{2} \mathrm{H}\right.$ ) was bought from IC Chemikalien (München, FRG). The gases were dried over molecular sieve $(3 \AA)$ and stored in a glass flask. Prior to use residual oxygen was removed by at least five freeze-pumpthaw cycles to a final pressure of $5(\mathrm{mPa})$.

\section{Results and Discussion \\ The Self-Diffusion Coefficient of Fluoroform}

In the absence of strong, anisotropic attractive interactions the structure and dynamics of liquids is dominated by short-ranged repulsive interactions. Thus the concept of the hard-spheres fluid as a zeroth order approximation to real liquids has been developed. For smooth hard spheres the self-diffusion coefficient may be expressed as [13]

$D_{\mathrm{SHS}}=\frac{3}{8}\left(\frac{k T}{m \cdot \pi}\right)^{1 / 2} \cdot d \cdot P\left(\varrho d^{3}\right)$

with $d$ the diameter of the spheres and $\varrho$ the number density. The coefficients of an empirical polynomial $P\left(\varrho d^{3}\right)$ in the
Table 1

Molecular constants in fluoroform

1) distances and angles

$$
\begin{aligned}
& r_{\mathrm{CF}}=1.39 \cdot 10^{-10}(\mathrm{~m}) \\
& r_{\mathrm{CH}}=1.09 \cdot 10^{-10}(\mathrm{~m}) \\
& r_{\mathrm{FF}}=2.166 \cdot 10^{-10}(\mathrm{~m}) \\
& r_{\mathrm{FH}}=1.997 \cdot 10^{-10}(\mathrm{~m})
\end{aligned}
$$

$\mathrm{FCF})=109$

$(\mathrm{FCH})=109$

2) dipole moment

$\mu=1.649(\mathrm{Dy})$

3) principal moments of inertia

$\mathrm{CHF}_{3}$

$$
\begin{aligned}
I_{\perp} & =81.60 \cdot 10^{-47}\left(\mathrm{~kg} \cdot \mathrm{m}^{2}\right) \\
I & =148.40 \cdot 10^{-47}\left(\mathrm{~kg} \cdot \mathrm{m}^{2}\right) \\
\langle I\rangle & =\left[\frac{1}{3}\left(\frac{1}{I_{1}}+\frac{2}{I_{\perp}}\right)\right]^{-1} \\
& =96 \cdot 10^{-47}\left(\mathrm{~kg} \cdot \mathrm{m}^{2}\right)
\end{aligned}
$$

$\mathrm{CDF}$

$85.61 \cdot 10^{-47}\left(\mathrm{~kg} \cdot \mathrm{m}^{2}\right)$ $148.40 \cdot 10^{-4^{-}}\left(\mathrm{kg} \cdot \mathrm{m}^{2}\right)$

$99.67 \cdot 10^{-47}\left(\mathrm{~kg} \cdot \mathrm{m}^{2}\right)$
4) principal spin-rotation tensor components

$\begin{aligned}{ }^{19} \mathrm{~F}: C_{\perp} & =8.83(\mathrm{kHz}) \\ C_{1} & =4.83(\mathrm{kHz})\end{aligned}$

'H: $C_{\perp}=0.667(\mathrm{kHz})$

$C_{1}=0.167(\mathrm{kHz})$

5) deuterium quadrupole coupling constants

$$
\begin{aligned}
& \frac{e^{2} q Q}{h}=170.8 \pm 2(\mathrm{kHz}) \text { gas } \\
& 159 \pm 5(\mathrm{kHz}) \text { liquid }
\end{aligned}
$$

packing fraction of the molecules have been obtained by forcing Eq. (1) to fit molecular dynamics results [14] of the hard sphere fluid. Rough hard spheres may represent nonspherical molecules or spherical molecules with anisotropic intermolecular interactions. A coupling of rotational and translational fluctuations must then be taken into account leading to a decrease of $D_{\mathrm{SHS}}$. Arguments have been put forward to account for the R-T-coupling simply by introducing a coupling parameter $A$ such that [15]

$D_{\text {exp }} \simeq D_{\mathrm{RHS}}=A_{\mathrm{RT}} \cdot D_{\mathrm{SHS}}$.

Table 2 compiles the self-diffusion coefficients measured together with the densities taken from the Refs. $[16,17]$. Fig. 1 shows the isobaric temperature dependence of the self-diffusion coefficient together with the data obtained previously [12]. Fig. 2 shows the isothermal density dependence of the self-diffusion coefficient $D$. The hard sphere diameter $d$ may be obtained from a non-linear least squares fit (NAG E04 FCF) to Eqs. (1) and (2). A temperature independent diameter $d=3.95 \AA$ results for $\mathrm{CHF}_{3}$. This compares favorably with the slightly smaller diameter $d=3.57 \AA$ obtained in $\mathrm{CH}_{3} \mathrm{~F}$ [18]. The temperature dependence of the slope $(\partial D / \partial \varrho)_{T}$ is predicted by Eq. (1) to be proportional to $T^{1 / 2}$. In most liquids, however, a stronger increase with temperature of the slope in the $D$ versus $\varrho$ plot is found. Hence the coupling of rotational and translational motions must depend on temperature. In fluoroform the R-T coupling parameter $A_{\mathrm{RT}}$ assumes values $\sim 0.3$ at low temperatures and increases towards 1.0 at the highest temperatures measured. 
This indicates an increased decoupling of rotation and translation with increasing temperature. Table 3 compares the hard sphere diameter and the R-T coupling parameter $A$ of

Table 2

Self-diffusion coefficient $D$ and mass density $\varrho$ of fluoroform $\left(T[\mathrm{~K}], p(\mathrm{MPa}], D\left[10^{-9} \mathrm{~m}^{2} \mathrm{~s}^{-1}\right], \varrho\left[\mathrm{kg} \cdot \mathrm{m}^{-3}\right]\right)$

\begin{tabular}{|c|c|c|c|c|c|c|c|}
\hline$T \backslash p$ & & SVP & 20 & 50 & 100 & 150 & 200 \\
\hline \multirow{2}{*}{142} & $D$ & 0.84 & 0.78 & 0.69 & 0.52 & 0.40 & \\
\hline & $\varrho$ & 1610 & 1650 & 1680 & 1730 & 1760 & \\
\hline \multirow{2}{*}{154} & & 1.25 & 1.15 & 0.96 & 0.74 & 0.57 & \\
\hline & & 1570 & 1610 & 1650 & 1700 & 1740 & \\
\hline \multirow{2}{*}{168} & & 1.90 & 1.70 & 1.45 & 1.10 & 0.86 & 0.70 \\
\hline & & 1530 & 1560 & 1610 & 1670 & 1710 & 1740 \\
\hline \multirow{2}{*}{177} & & 2.35 & 2.00 & 1.65 & 1.30 & 1.05 & 0.89 \\
\hline & & 1500 & 1540 & 1590 & 1650 & 1700 & 1720 \\
\hline \multirow{2}{*}{188} & & 2.85 & 2.50 & 2.20 & 1.70 & 1.37 & 1.15 \\
\hline & & 1460 & 1500 & 1560 & 1630 & 1680 & 1710 \\
\hline \multirow{2}{*}{208} & & 4.40 & 3.70 & 3.10 & 2.50 & 2.10 & 1.70 \\
\hline & & 1380 & 1440 & 1510 & 1580 & 1640 & 1670 \\
\hline \multirow{2}{*}{222} & & 5.50 & 4.70 & 3.65 & 2.95 & 2.40 & 2.10 \\
\hline & & 1330 & 1390 & 1470 & 1550 & 1610 & 1650 \\
\hline \multirow{2}{*}{250} & & 8.00 & 6.80 & 5.60 & 4.40 & 3.60 & 3.20 \\
\hline & & 1180 & 1280 & 1390 & 1490 & 1560 & 1610 \\
\hline \multirow{2}{*}{262} & & & 8.00 & 6.20 & 4.70 & 3.80 & 3.40 \\
\hline & & & 1250 & 1350 & 1460 & 1540 & 1590 \\
\hline \multirow{2}{*}{291} & & & 11.20 & 8.50 & 6.40 & 5.20 & 4.10 \\
\hline & & & 1130 & 1270 & 1400 & 1490 & 1540 \\
\hline \multirow{2}{*}{322} & & & 17.00 & 11.50 & 8.20 & 6.70 & 5.60 \\
\hline & & & 980 & 1180 & 1340 & 1430 & 1490 \\
\hline \multirow[t]{2}{*}{353} & & & 24.00 & 15.00 & 10.50 & 8.50 & 7.00 \\
\hline & & & 800 & 1090 & 1270 & 1370 & 1440 \\
\hline \multirow{2}{*}{383} & & & 32.50 & 19.00 & 13.00 & 10.00 & 8.30 \\
\hline & & & 650 & 1010 & 1210 & 1320 & 1390 \\
\hline \multirow{2}{*}{433} & & & 53.00 & 26.50 & 18.50 & 13.00 & 10.50 \\
\hline & & & & 860 & 1100 & 1230 & 1320 \\
\hline
\end{tabular}

Table 3

Rough hard sphere diameter $d[\mathrm{~nm}]$ and rotation-translation coupling parameter $A_{\mathrm{RT}}$ of fluoroform and related halomethanes

\begin{tabular}{llllll}
\hline & $\mathrm{CH}_{3} \mathrm{~F}$ & \multicolumn{1}{c}{$\mathrm{CHF}_{3}$} & \multicolumn{1}{c}{$\mathrm{CH}_{3} \mathrm{Cl}$} & $\mathrm{CH}_{2} \mathrm{Cl}_{2}$ & \multicolumn{1}{c}{$\mathrm{CHCl}_{3}$} \\
\hline$T(\mathrm{~K})$ & $150-440$ & $142-420$ & $185-440$ & $186-406$ & $230-400$ \\
$d(\mathrm{~nm})$ & 0.357 & 0.395 & 0.40 & 0.44 & 0.48 \\
$A_{\mathrm{RT}}$ & $0.4-1.0$ & $0.3-1.0$ & $0.4-0.75$ & $0.3-0.8$ & $0.4-0.8$ \\
\hline
\end{tabular}

Table 4

Comparison of self-diffusion coefficients $D$ and integral orientational correlation times $\tau_{2, i}$ as obtained by MD simulations with experimental results of fluoroform

\begin{tabular}{lllll}
\hline & MD & \multicolumn{2}{c}{ Expt. } \\
\hline$T[\mathrm{~K}]$ & 250 & 136 & 250 & 136 \\
$\varrho\left[\mathrm{kg} \cdot \mathrm{m}^{-3}\right]$ & 1390 & 1640 & 1390 & 1640 \\
$D\left[10^{9} \mathrm{~m}^{2} \mathrm{~s}^{-1}\right]$ & 4.1 & 0.5 & 5.5 & $0.58^{\text {a) }}$ \\
$\tau_{2, i}[\mathrm{ps}]$ & 0.55 & 3.0 & 0.58 & $2.6^{\text {a) }}$ \\
\hline
\end{tabular}

a) Obtained by slight extrapolation. fluoroform with methylfluoride [18] and related halomethanes [19]. Fig. 3 compares the temperature dependence of the parameter $A_{\mathrm{RT}}$ in fluoroform, methylfluoride [18] and Carbon tetrafluoride [20]. Recently Böhm et al. [21] devised an intermolecular pair potential and applied it to a number of molecules including those listed in Table 3 . Their calculated self-diffusion coefficients are in fair agreement with experiment. Notably their self-diffusion coefficient in fluoroform is in good agreement with those obtained in this study. However, both are in substantial disagreement with results obtained earlier by Chaffin et al. [3]. Table 4 gives

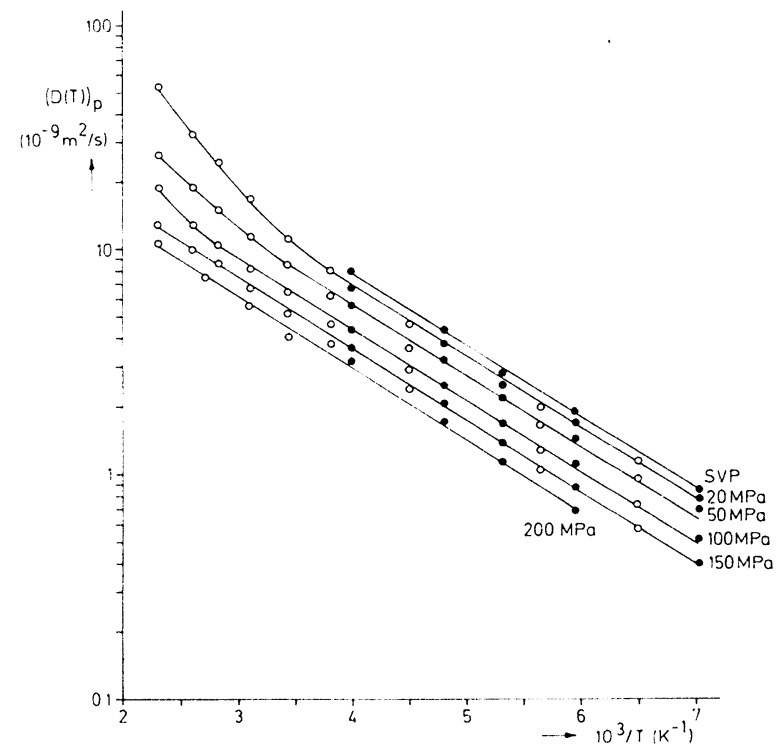

Fig. 1

Isobaric temperature dependence of the self-diffusion coefficient $D$ in $\mathrm{CHF}_{3}$. $\left(\mathrm{XL}_{-100}\left({ }^{1} \mathrm{H}\right), \mathrm{OMSL}-300\left({ }^{19} \mathrm{~F}\right)\right)$

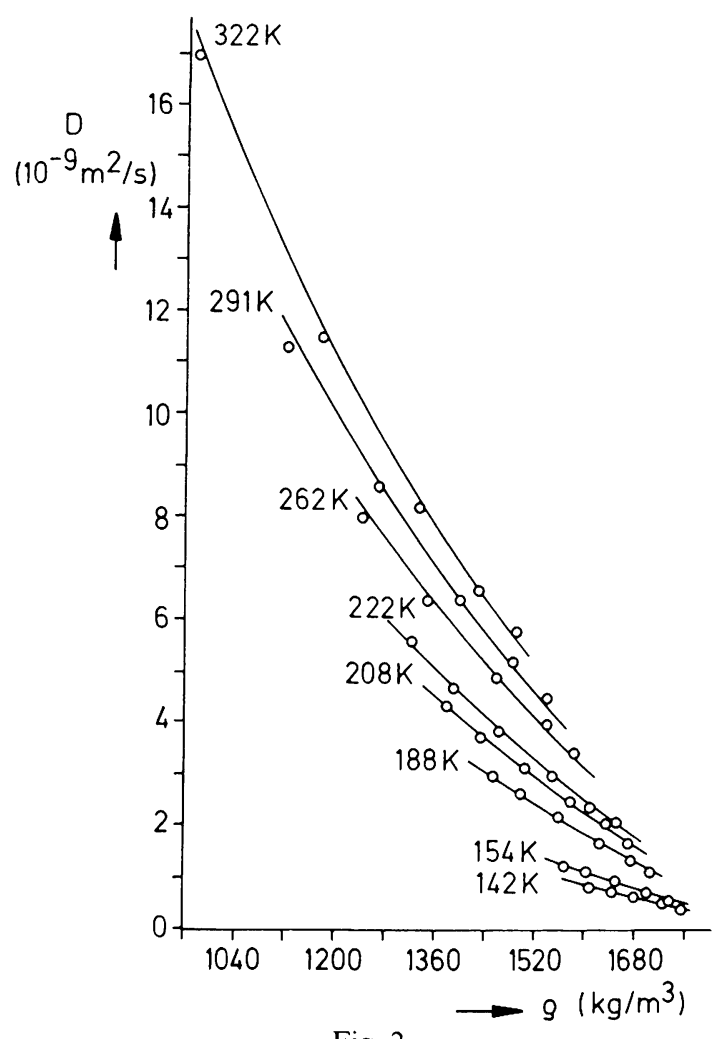

Fig. 2

Isothermal density dependence of the self-diffusion coefficient $D$ in $\mathrm{CHF}_{3}$. - Best fit curve according to Eqs. (1) and (2) 
a comparison of dynamic parameters obtained with molecular dynamics calculations and experimental results obtained in our group [12,18,19].

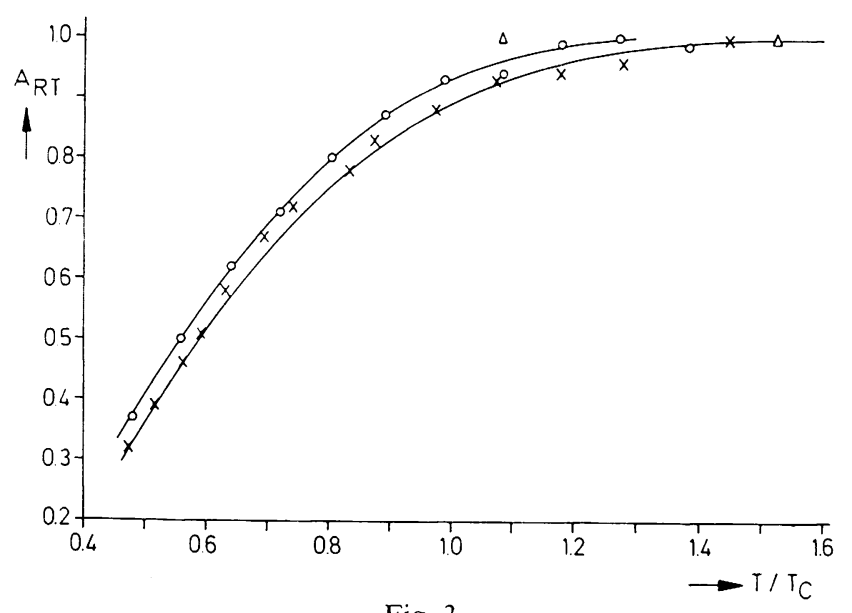

Fig. 3

Temperature dependence of the rotation-translation parameter $A_{\mathrm{RT}}$ in $\mathrm{CH}_{3} \mathrm{~F}(\mathrm{O}), \mathrm{CHF}_{3}(\times)$ and $\mathrm{CF}_{4}(\triangle)[20]$

\section{Deuterium Spin-Lattice Relaxation Rates in $\mathrm{CDF}_{3}$}

The spin-lattice relaxation of ${ }^{2} \mathrm{D}$ nuclei is almost exclusively due to fluctuating electric field gradients interacting with the electric quadrupole moment of the nucleus. Presuming rigid molecules of spherical shape the relaxation rate is given in the short correlation time limit in a laboratoryfixed frame as [22]

$R_{1}^{\mathrm{Q}}=\frac{3 \pi^{2}}{10}\left(\frac{e^{2} q_{z}^{\mathrm{M}} Q}{h}\right)^{2}\left(1+\frac{\eta^{2}}{3}\right)\left(\frac{2 I+3}{I^{2}(2 I-1)}\right) \cdot \tau_{0,2}^{Q}$

where $I=1$ is the spin quantum number of the deuterium nucleus. $\left(e^{2} q_{z:}^{\mathrm{M}} Q / h\right)$ is the quadrupole coupling constant in

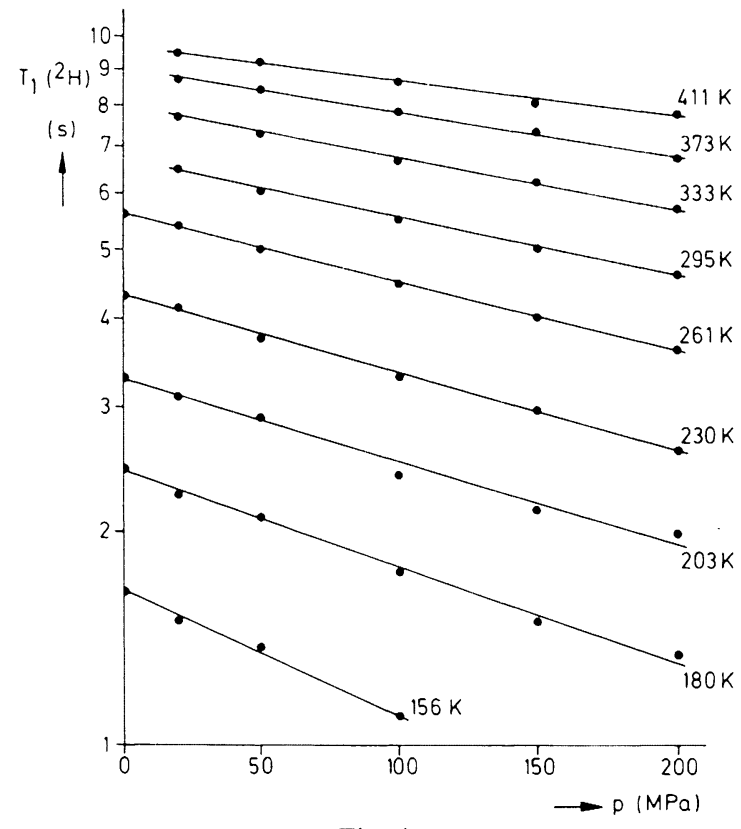

Fig. 4

Isothermal pressure dependence of the deuterium spin-lattice relaxation time $\left(T_{1}\left({ }^{2} \mathrm{H}\right)\right.$ in $\mathrm{CDF}_{3}$ hertz with $e Q$ the electric quadrupole moment and $e q_{: z}^{\mathrm{M}}$ the largest component of the electric field gradient (efg) tensor along the C-D bond in a molecule fixed axis system. The efg asymmetry parameter $\eta=\left(q_{x x}^{\mathrm{M}}-q_{y y}^{\mathrm{M}}\right) / q_{z:}^{\mathrm{M}}$ is generally small and will be neglected. Fig. 4 shows the isothermal pressure dependence of the ${ }^{2} \mathrm{D}-\mathrm{T}_{1}$ in $\mathrm{CDF}_{3}$.

The orientational correlation time $\tau_{0.2}$ is defined as the integral over the normalized orientational correlation function of elements of the Wigner rotation matrix specifying the orientation of the main axis system of the efg tensor relativ to the laboratory frame. In principle, because $\mathrm{CDF}_{3}$ is a symmetric top and because the deuterium nucleus is on the symmetry axis of the molecule, $\tau_{0,2}$ monitors only orientational fluctuations of the $\mathrm{C}_{3}$-axis.

The deuterium quadrupole coupling constant has been obtained in the gas phase to $170.8 \pm 2 \mathrm{kHz}$ [23]. Utilizing correlation times extracted from Raman line shape studies [10] and deuterium relaxation rates [4] a substantially lower value of $159 \pm 5 \mathrm{kHz}$ has been reported for liquid $\mathrm{CDF}_{3}$. This is in good accord with the general finding that deuterium quadrupole coupling constants are reduced by $\sim 10 \%$ roughly in going from the gas phase to the solid state. The latter value will be used in this study to calculate the correlation times $\tau_{0,2}$.

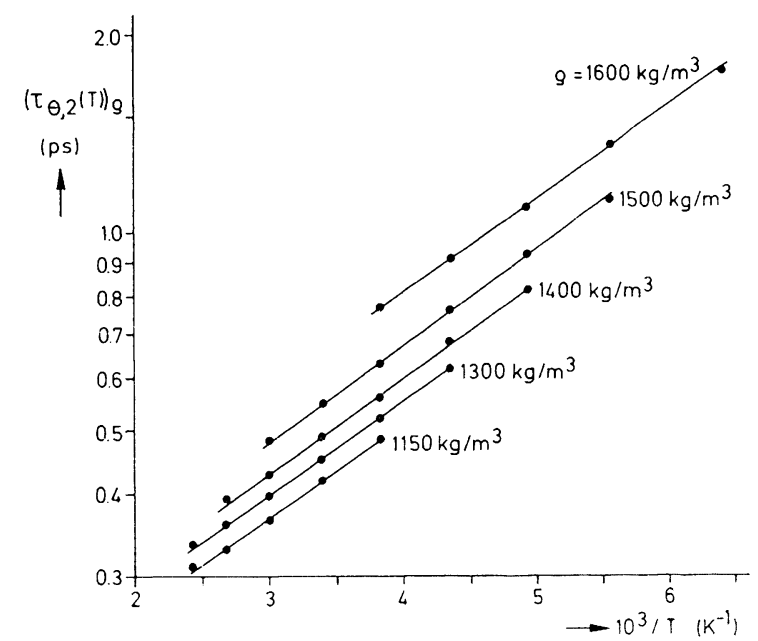

Fig. 5

Isochoric temperature dependence of the orientational correlation time $\tau_{t, 2}$ in $\mathrm{CDF}_{3}$

Fig. 5 shows their isochoric temperature dependence. At constant density the temperature dependence reflects the sole influence of the kinetic energy of the molecules upon orientational fluctuations. Because intermolecular torques fluctuate more rapidly at higher temperatures, orientational correlations decay on a shorter time scale leading to decreasing correlation times. The latter are seen to be longer than those obtained in methylfluoride indicating stronger intermolecular torques retarding rotational motions. Indeed fairly high root mean square intermolecular torques have been found to prevail in fluoroform along the orthobar [7]. The isochoric temperature dependence of $\tau_{0.2}$ follows an Arrhenius law with a density independent activation energy $E_{Q}^{*}=2.75 \mathrm{~kJ} / \mathrm{mol}$. This is about half the value $\left(E_{\mathrm{A}}^{*}=4.6\right.$ 


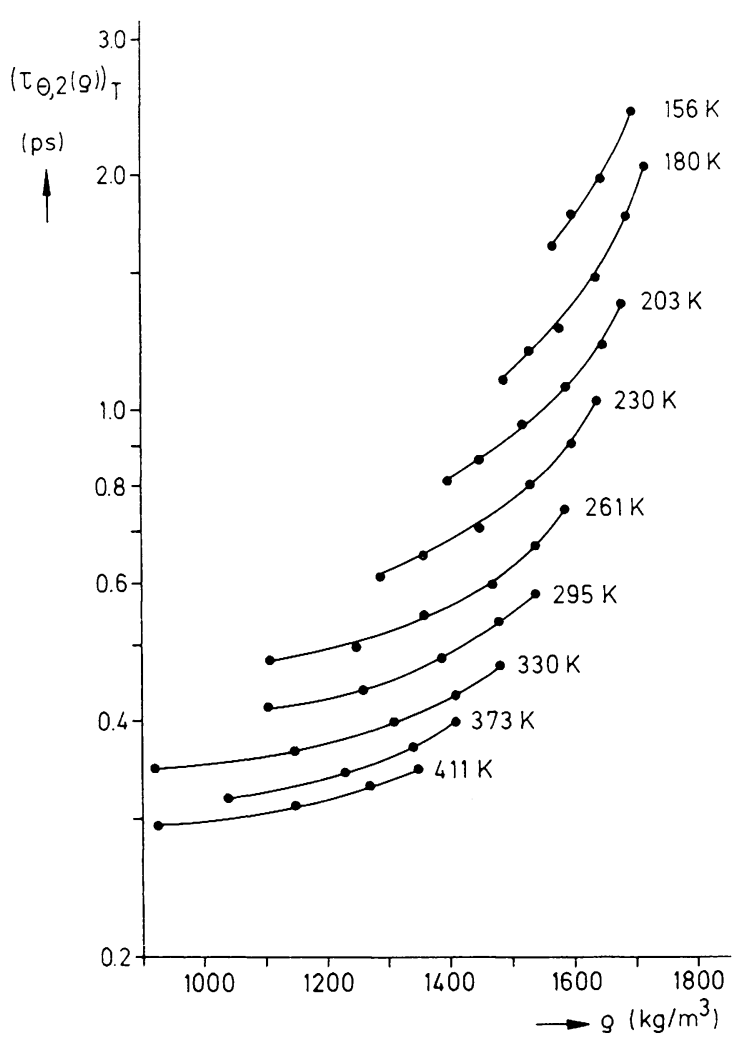

Fig. 6

Isothermal density dependence of the orientational correlation time $\tau_{0,2}$ in $\mathrm{CDF}_{3}$

$\mathrm{kJ} / \mathrm{mol}$ ) obtained from dielectric data along the orthobar [7]. The ratio $E_{A}^{\#} / E_{\varrho}^{\#} \sim 1.6$ in methylfluoride [18] and fluoroform. Compared to methylfluoride the isochoric temperature dependence $\left(E_{\varrho}^{\#}=2.40(\mathrm{~kJ} / \mathrm{mol})\right)$ as well as the isothermal density dependence of orientational fluctuations (Fig. 6) is found to be slightly stronger in fluoroform. At constant temperature the correlation times increase in a nonlinear fashion with density, reflecting the retarding influence of molecular torques upon the reorientation process at higher packing fractions. The increase is the more pronounced the lower the temperature (see Fig. 6). The fairly short correlation times $\tau_{0,2}$ and the low barrier to rotation suggest the importance of inertial effects during the reorientation process. An indication may be obtained by comparing the orientation correlation times $\tau_{0,2}$ with the free rotor correlation time $\tau_{\mathrm{f}}=\frac{3}{5} \sqrt{\frac{\langle I\rangle}{\mathrm{kT}}}$. If the ratio $\tau_{0.2} / \tau_{\mathrm{f}} \gg 1$, reorientational processes are diffusive and inertial effects may be neglected. If $\tau_{0,2} / \tau_{\mathrm{f}} \simeq 1$ inertial effects severely influence orientational correlation functions. In $\mathrm{CDF}_{3}$ at low temperatures the ratio $\tau_{0,2} / \tau_{\text {f }}$ yields values $\sim 6$ whereas at high temperatures values $\sim 1.5$ are found. Hence in analogy to methylfluoride the molecular dynamics of fluoroform do not correspond to a small step diffusive process over most of the $p, T$-range investigated. Finally a comparison of $\tau_{0.2}$ with molecular dynamics results [21] indicates good agreement as has also been found in the case of the self-diffusion data (see Table 4).

\section{${ }^{1} \mathbf{H}$ and ${ }^{19} \mathrm{~F}$ Spin-Lattice Relaxation Rates in $\mathrm{CHF}_{\mathbf{3}}$}

The spin-lattice relaxation of the protons and fluorine nuclei proceeds mainly via magnetic dipole-dipole interactions and spin-rotation interactions. The dipolar interactions have to be decomposed into intra- and intermolecular interactions. In the short correlation time limit the various dipolar relaxation rates are given, again presuming rigid molecules of spherical shape, as [22]

a) dipole-dipole, intra

$$
\begin{aligned}
R_{1, \mathrm{dd}}^{\mathrm{intra}}= & \left(\frac{\mu_{0}}{4 \pi}\right)^{2} \frac{3}{2} \hbar^{2} \gamma_{I}^{4} \cdot \frac{2}{n}\left(\sum_{i>j}^{n} r_{i j}^{-6}\right) \tau_{0,2}^{\mathrm{dd}}(I-I) \\
& +\hbar^{2} \gamma_{I}^{2} \gamma_{S}^{2} \cdot\left(\frac{\mu_{0}}{4 \pi}\right)^{2} \cdot \sum_{S} r_{I S}^{-6} \cdot \tau_{0,2}^{\mathrm{dd}}(I-S)
\end{aligned}
$$

with $I(S)$ representing the spin quantum number of the fluorine (proton) nuclei and $n$ the number of spins per molecule.

b) dipole-dipole, inter

$$
\begin{aligned}
R_{1, \mathrm{dd}}^{\mathrm{inter}}= & \frac{8 \pi}{9}\left(\gamma_{i}^{2} \cdot \frac{\mu_{0}}{4 \pi}\right)^{2} \cdot \hbar^{2} \cdot \frac{n_{l}}{D} \sum_{i \neq j} a_{i j}^{-1} \\
& +\frac{16}{27}\left(\gamma_{S} \gamma_{l} \frac{\mu_{0}}{4 \pi}\right)^{2} \cdot \hbar^{2} \cdot \frac{n_{S}}{D} \sum_{S} a_{I S}^{-1} .
\end{aligned}
$$

The expressions for the intermolecular relaxation rate may be obtained with a diffusion equation with reflecting boundary conditions $[24,25]$. Any off-center effects have been neglected as they contribute less than $10 \%$ to the leading term [26]. The relative diffusion coefficient has been replaced by twice the measured self-diffusion coefficient. The distance of closest approach a has been taken from radial pair-distribution functions as obtained by the molecular dynamics simulations of Böhm et al. [21].

The intramolecular dipolar relaxation rates may be obtained from Eq. (4) if $\tau_{0.2}^{\mathrm{dd}}$ is replaced by $\tau_{0.2}^{Q}$. This should be a reasonable approximation because $\mathrm{CDF}_{3}$ and $\mathrm{CHF}_{3}$ possess very similar moments of inertia. Also intermolecular interactions cannot differ much, hence one may not expect a significant isotope effect on the correlation times. Furthermore orientational fluctuations in fluoroform have been shown to be nearly isotropic and the numerical identity $\tau_{0,2}^{\mathrm{dd}}=\tau_{0,2}^{Q}$ has been demonstrated $[4,10]$.

The spin-rotation relaxation rate is given for a spherical top by [27]

$R_{1}^{\mathrm{SR}}=\frac{2 k_{\mathrm{B}} T}{\hbar^{2}} \cdot\langle I\rangle \sum_{i}\left[C_{0, i}^{2} \cdot \tau_{(1)}+2(\Delta C)_{i}^{2} \cdot \tau_{\mathrm{SR}}\right]$

with $\langle I\rangle=\left[\frac{1}{3} \sum 1 / I_{i}\right)^{-1}$ the mean moment of inertia of the molecule. $C_{0}=\frac{1}{3}\left(C_{\|}+2 C_{\perp}\right)$ and $\Delta C=\frac{1}{3}\left(C_{\|}-C_{\perp}\right)$ give the isotropic and the anisotropic part of the spin-rotation tensor in terms of the parallel and perpendicular component of the tensor in its main axis system. $\tau_{\omega \nu}$ is the correlation time for fluctuations of the molecular angular velocity and $\tau_{\mathrm{SR}}$ is the correlation time for the angular velocity-orientational product correlation function which characterizes an- 
isotropic spin-rotational interactions. Eq. (6) is equivalent to an expression given by Hubbard [28,29]

$R_{1}^{\mathrm{SR}}=\frac{2 k_{\mathrm{B}} T}{\hbar^{2}}\langle I\rangle \sum_{i} \frac{1}{3}\left(C_{\mathrm{H}, i}^{2}+2 C_{\perp, i}^{2}\right) \cdot \tau_{\mathrm{SR}}$

if due account is taken of the different definitions of $\tau_{\mathrm{SR}}$. Eq. (7) has been used to calculate the correlation times $\tau_{\mathrm{SR}}$.

\section{Separation of the ${ }^{19} \mathrm{~F}$ Relaxation Rates in $\mathrm{CHF}_{3}$ and $\mathrm{CDF}_{3}$}

The ${ }^{19} \mathrm{~F}$ spin-lattice relaxation rate is a sum of different contributions according to

$$
\begin{aligned}
R_{1}\left({ }^{19} \mathrm{~F}\right)= & R_{1}^{\mathrm{SR}}\left({ }^{19} \mathrm{~F}\right)+R_{1, d d}^{\text {intra }}\left({ }^{19} \mathrm{~F}-{ }^{19} \mathrm{~F}\right)+R_{1, d d}^{\text {intra }}\left({ }^{19} \mathrm{~F}-{ }^{1} \mathrm{H}\right) \\
& +R_{1, d d}^{\text {inter }}\left({ }^{9} \mathrm{~F}-{ }^{-19} \mathrm{~F}\right)+R_{1, d d}^{\text {inter }}\left({ }^{19} \mathrm{~F}-{ }^{1} \mathrm{H}\right) .
\end{aligned}
$$

Relaxation due to anisotropic chemical shielding of the fluorine nucleus has been shown to be negligible $[3,4]$. This is corroborated by the agreement of both sets of data obtained at ambient pressure, where no field dependence could be detected. In $\mathrm{CDF}_{3}$ the dipolar interactions between the ${ }^{19} \mathrm{~F}$ - and the ${ }^{2} \mathrm{H}$ nuclei may be neglected because of the much smaller gyromagnetic ratio of the deuterium nucleus. The pressure and temperature dependence of the experimental

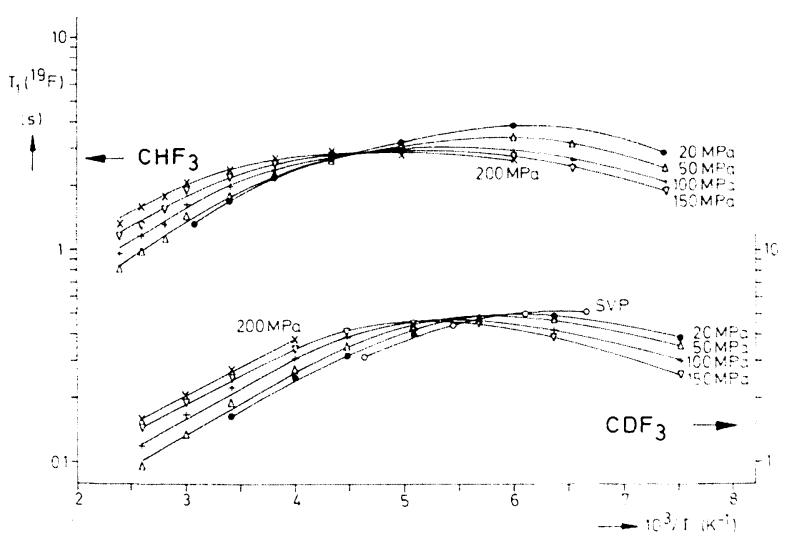

Fig. 7

Isobaric temperature dependence of the fluor-19 spin-lattice relaxation time in $\mathrm{CHF}_{3}$ and $\mathrm{CDF}_{3}$

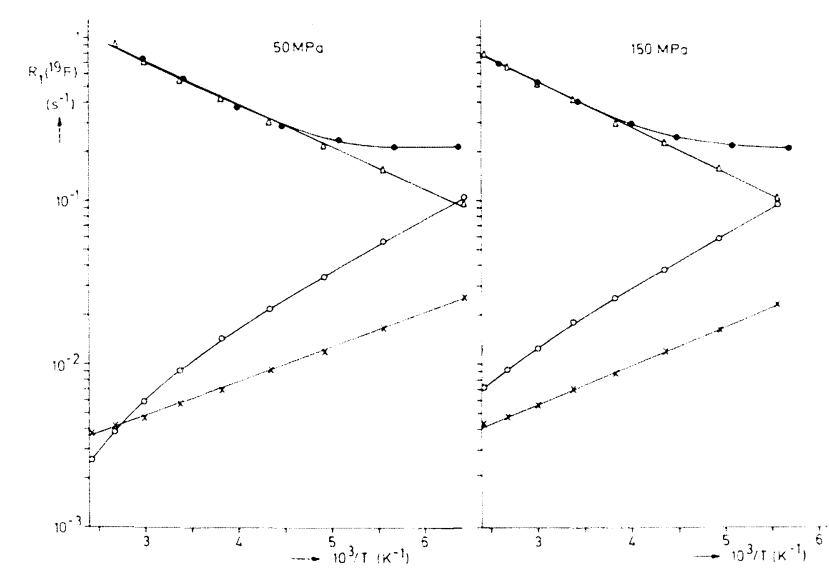

Fig. 8

Temperature dependence of the various relaxation rates contributing to the total fluor-19 spin-lattice relaxation rate in $\mathrm{CDF}_{3}$ at two pressures $\left(\bullet R_{1}\left({ }^{19} \mathrm{~F}\right), \triangle R_{1}^{\mathrm{SR}}, \bigcirc R_{1, d d}^{\text {inter }}, \times R_{1, d d}^{\text {intraa }}\right)$
${ }^{19} \mathrm{~F}$ spin-lattice relaxation times are shown in Fig. 7 for $\mathrm{CHF}_{3}$ and $\mathrm{CDF}_{3}$. The spin-rotation interaction dominates over most of the temperature range investigated. At the highest temperatures the spin-rotation relaxation rates are almost identical with the total rate measured. Also at these temperatures the relaxation rates observed in $\mathrm{CHF}_{3}$ and $\mathrm{CDF}_{3}$ are identical. This is to be expected because of the small isotope effect upon the components of the moment of inertia tensor $\mathbf{I}$. At low temperatures the relaxation rates are larger in $\mathrm{CHF}_{3}$ than in $\mathrm{CDF}_{3}$ because of the additional ${ }^{19} \mathrm{~F}^{-1} \mathrm{H}$ dipolar contributions to the total rate measured. The intraand intermolecular dipolar rates have been calculated as described above using a distance of closest approach $a\left({ }^{19} \mathrm{~F}\right.$ $\left.{ }^{19} \mathrm{~F}\right)=2.5 \AA$ and $a\left({ }^{19} \mathrm{~F}-{ }^{1} \mathrm{H}\right)=2.2 \AA$ and are shown for two pressures in Fig. 8. Subtracting these contributions from the total rate measured, the spin-rotation relaxation rate may be obtained. To calculate correlation times $\tau_{\mathrm{SR}}$ with Eq. (7) independent information about the components of the spinrotation tensor is necessary. Reynders et al. [30] measured the hyperfine structure of the $J=1 \rightarrow 0$ rotational transition with a high-resolution beam-maser spectrometer and report the coupling constant $C_{10}\left({ }^{19} \mathrm{~F}\right)=\sum_{i=1}^{3} \frac{1}{2}\left(C_{\text {a: }}^{i}+C_{\mathrm{bb}}^{i}\right)$ $=10.6 \pm 1(\mathrm{kHz})$ in the principal axis system of the moment of inertia tensor, while Kukolich et al. [23] obtained a hyperfine constant for the same transition of $C_{10}\left({ }^{19} \mathrm{~F}\right)=5.4 \pm$ $1.5(\mathrm{kHz})$. Besides the large discrepancy between both results, these coupling constants are insufficient to determine all components of the spin-rotation tensor $\mathbf{C}$. Molecular beam determination of the spin-rotation constants as obtained by Follett $[31,32]$ yield $\frac{1}{3}\left(C_{x x}+C_{y y}+C_{z z}\right)=7.5$ $\pm 1.2 \mathrm{kHz}$ and $\frac{1}{2}\left(C_{x x}+C_{y r}-C_{z z}\right) \leqslant 4 \mathrm{kHz}$. These may be rearranged to give $C_{z z}=C_{\|}=4.83(\mathrm{kHz})$ and $\frac{1}{2}\left(C_{x x}+\right.$ $\left.C_{y y}\right)=C_{\perp}=8.83(\mathrm{kHz})$ to be used in Eq. (7) to calculate spin-rotation correlation times $\tau_{\mathrm{SR}}$. These coupling constants are in better accord with the results of Reynders et al. [30] than with those obtained by Kukolich et al. [23]. Dong and Bloom [33] and Armstrong and Courtney [32] obtained an effective spin-rotation coupling constant $C_{\text {eff }}^{2}\left({ }^{i 9} \mathrm{~F}\right)=48.1 \pm 2.1(\mathrm{kHz})^{2}$ and $76<C_{\text {efr }}^{2}\left({ }^{19} \mathrm{~F}\right)<94(\mathrm{kHz})^{2}$ respectively from ${ }^{19} \mathrm{~F}-\mathrm{T}_{1}$ measurements of gaseous $\mathrm{CHF}_{3}$, whereas $C_{\text {eff }}^{2}=63.45(\mathrm{kHz})^{2}$ is calculated by Sanctuary [34] with the components $C_{\|}, C_{\perp}$ as evaluated from the results of Follett [31].

Fig. 9 shows the isothermal density dependence and the isochoric temperature dependence of the reduced correlation times $\tau_{\mathrm{SR}}^{*}=(k T /\langle I\rangle)^{1 / 2} \cdot \tau_{\mathrm{SR}}$. With increasing density $\tau_{\mathrm{SR}}^{*}$ decreases due to the stronger perturbing influence of molecular torques at higher packing fractions. The decrease is the more pronounced the lower the temperature and/or the higher the density. The isothermal density dependence of $\tau_{\mathrm{SR}}^{*}$ is stronger in fluoroform than in methylfluoride at comparable temperatures. At the lowest temperatures the condition $\tau_{\mathrm{SR}} \ll \tau_{0,2}$ holds corresponding to a rotational diffusion process. The isochoric temperature dependence of $\tau_{\mathrm{SR}}^{*}$ (see Fig. 10) shows an Arrhenius-dependence with an apparent, density independent, activation energy of $E_{0}^{\#}=2.05$ $(\mathrm{kJ} / \mathrm{mol})$. This is $\sim 3 / 4$ of the activation energy $E_{0}^{*}=2.75$ $(\mathrm{kJ} / \mathrm{mol})$ found for the isochoric temperature dependence of $\tau_{0.2}$. It is interesting to note that in methylfluoride an ap- 
parent activation energy $E_{0}^{*} \simeq 2.17(\mathrm{~kJ} / \mathrm{mol})$ has been found at a density $\varrho=1.0\left(\mathrm{~g} / \mathrm{cm}^{3}\right)$ which is about the highest density obtained in $\mathrm{CH}_{3} \mathrm{~F}$ whereas it is roughly the lowest density obtained in $\mathrm{CHF}_{3}$. It should be noticed, however, that the number densities corresponding to a mass density range $\varrho$ : $300-1100\left(\mathrm{~kg} / \mathrm{m}^{3}\right)$ in $\mathrm{CH}_{3} \mathrm{~F}$ and $\varrho$ : $900-1700$ $\left(\mathrm{kg} / \mathrm{m}^{3}\right)$ covered by the experiments are practically identical in both substances. At lower densities deviations from an Arrhenius-dependence have been observed in methylfluoride with a weaker temperature dependence at lower densities contrary to the density independent activation energy found in fluoroform.

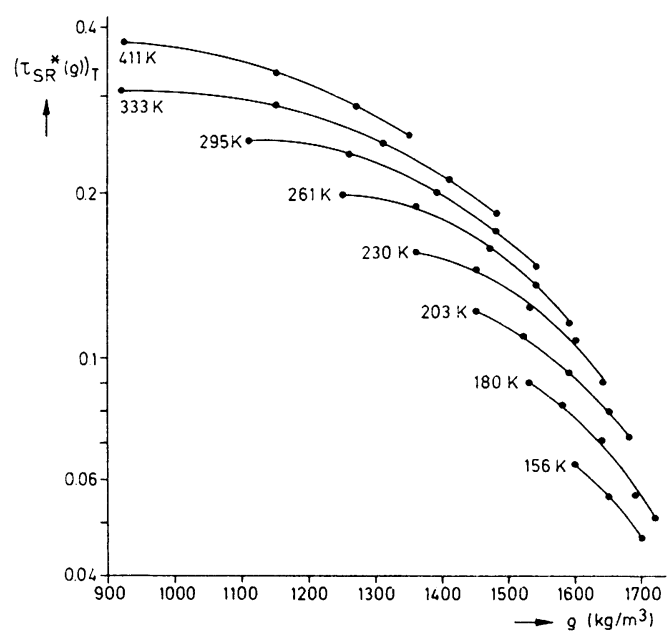

Fig. 9

Isothermal density dependence of the reduced spin-rotation correlation time $\tau_{S R}^{*}$

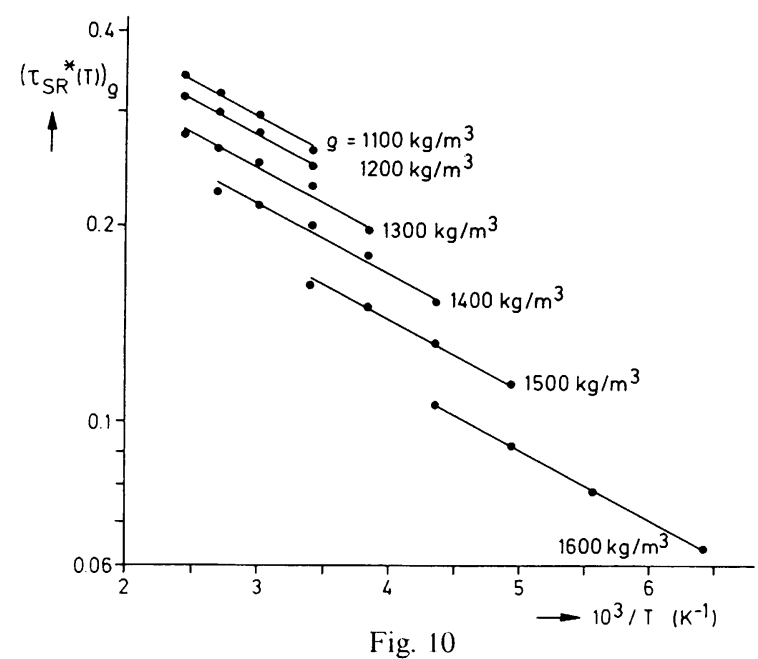

Isochoric temperature dependence of the reduced spin-rotation correlation time $\tau_{\mathrm{SR}}^{*}$

\section{Separation of the ${ }^{\mathbf{1}} \mathrm{H}$ Relaxation Rates in $\mathrm{CHF}_{3}$}

The proton spin-lattice relaxation rate is a sum of different contributions according to

$$
\left\{\begin{aligned}
R_{1}\left({ }^{1} \mathrm{H}\right)= & R_{1, \mathrm{dd}}^{\text {intra }}\left({ }^{1} \mathrm{H}-{ }^{19} \mathrm{~F}\right)+R_{1, \mathrm{dd}}^{\text {inter }}\left({ }^{1} \mathrm{H}-{ }^{19} \mathrm{~F}\right) \\
& +R_{1, \mathrm{dd}}^{\text {inter }}\left({ }^{1} \mathrm{H}-{ }^{1} \mathrm{H}\right)+R_{1}^{\mathrm{SR}} .
\end{aligned}\right.
$$

The pressure and temperature dependence of the proton spin-lattice relaxation times $T_{1}$ is shown in Fig. 11. The

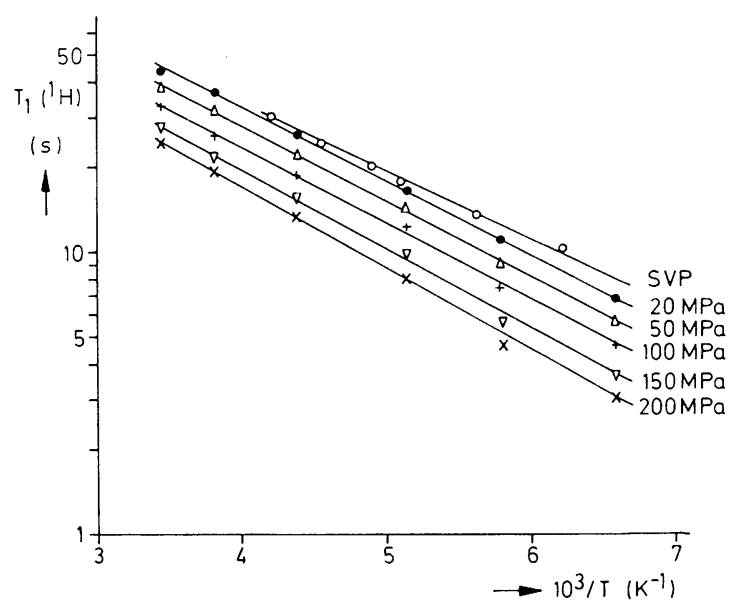

Fig. 11

Isobaric temperature dependence of the proton spin-lattice relaxation time $T_{1}\left({ }^{1} \mathrm{H}\right)$ in $\mathrm{CHF}_{3}$

intermolecular dipolar relaxation rates have been calculated with Eq. (5) using the measured self-diffusion coefficient $D$ and distances of closest approach $a\left({ }^{1} \mathrm{H}^{-}{ }^{1} \mathrm{H}\right)=3.6 \AA$ and $a\left({ }^{1} \mathrm{H}-{ }^{19} \mathrm{~F}\right)=2.2 \AA$ as estimated from the radial pair distribution functions [21]. The densities have been taken from Refs. $[16,17]$. The intramolecular dipolar relaxation rates have been calculated with Eq. (4) and with $\tau_{0.2}^{\mathrm{dd}}$ replaced by $\tau \varnothing .2$ because of the near isotropy of orientational fluctuations in fluoroform and because of the negligible isotope effect. The spin-rotation relaxation rates $R_{1}^{\mathrm{SR}}$ have been calculated with Eq. (7) with $\tau_{S R}^{*}$ as deduced from the fluorine spinrotation relaxation rates. Several determinations of the hyperfine constants of $\mathrm{CHF}_{3}$ have been reported in the literature. Reynders et al. [30] obtained $C_{10}^{(\mathrm{H})}=C_{\perp}=0.0 \pm 1$ $(\mathrm{kHz})$ whereas Kukolich et al. [23] obtained for the same transition $C_{10}^{(\mathrm{H})}=24.5 \pm 3(\mathrm{kHz})$ in sharp disagreement with the results of Reynders et al. [30]. Follett [31] reports $C_{\mathrm{a}}=\frac{1}{3}\left(C_{x x}+C_{y y}+C_{z z}\right)=0.5 \pm 0.1(\mathrm{kHz})$ and $C_{\mathrm{d}}=\frac{1}{2}\left(C_{x x}\right.$ $\left.+C_{y y}\right)-C_{z z}=0.5 \pm 0.1(\mathrm{kHz})$ yielding $C_{\|}=0.167(\mathrm{kHz})$ and $C_{\perp}=0.667(\mathrm{kHz})$ in good agreement with the results obtained by Reynders et al. [30]. Dong and Bloom obtained an effective spin-rotation constant $C_{\text {eff }}^{2}\left({ }^{1} \mathrm{H}\right)=0.40 \pm 0.05$ $(\mathrm{kHz})$, whereas Armstrong and Courtney [32] give $0.2<$ $\left.C_{\text {eff }}^{2}{ }^{1} \mathrm{H}\right)<0.3(\mathrm{kHz})^{2}$. Using the results of Follett [31] $C_{\text {eff }}^{2}\left({ }^{1} \mathrm{H}\right)=0.3(\mathrm{kHz})^{2}$ is calculated in reasonable agreement with the estimates given above. The calculated relaxation rates $R_{1}^{\mathrm{SR}}\left({ }^{1} \mathrm{H}\right)$ are very small, thus may be neglected at all but the highest temperatures. The experimental $R_{1}^{\mathrm{SR}}\left({ }^{1} \mathrm{H}\right)$ obtained by subtracting all dipolar relaxation rates from $R_{1}^{\exp }\left({ }^{1} \mathrm{H}\right)$ are $2-3$ times larger than the rates estimated with Eq. (7). This may be partly due to the large errors involved in estimating experimental $R_{1}^{\mathrm{SR}}\left({ }^{1} \mathrm{H}\right)$ as a difference of large numbers and partly due to the approximations inherent in the calculation of $R_{1, d d}^{\text {inter }}\left({ }^{1} \mathrm{H}\right)$. Fig. 12 gives the temperature dependence of the various contributions of Eq. (9) to the total rate at three different pressures.

\section{Orientational $\left(\tau_{2}\right)$ and Spin-Rotational $\left(\tau_{S R}\right)$ Correlation Times in Fluoroform}

Only integral orientational correlation times could be determined in this study. The orientational correlation func- 

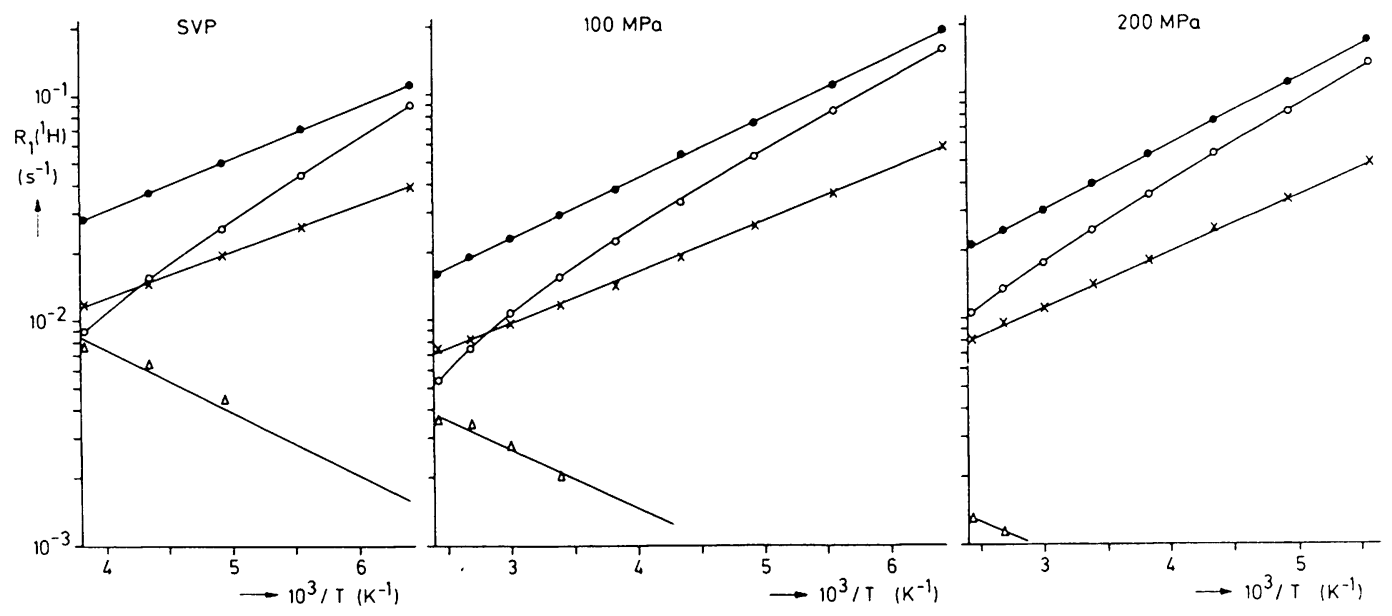

Fig 12

Temperature dependence of the various relaxation rates contributing to the total proton spin-lattice relaxation rate in $\mathrm{CHF}_{3}$ at three pressures $\left(\bullet R_{1}\left({ }^{1} \mathrm{H}\right), \bigcirc R_{1, d d}^{\text {inter }}, \times R_{1, d d}^{\text {intra, }}, \triangle R_{1}^{\mathrm{SR}}\right)$

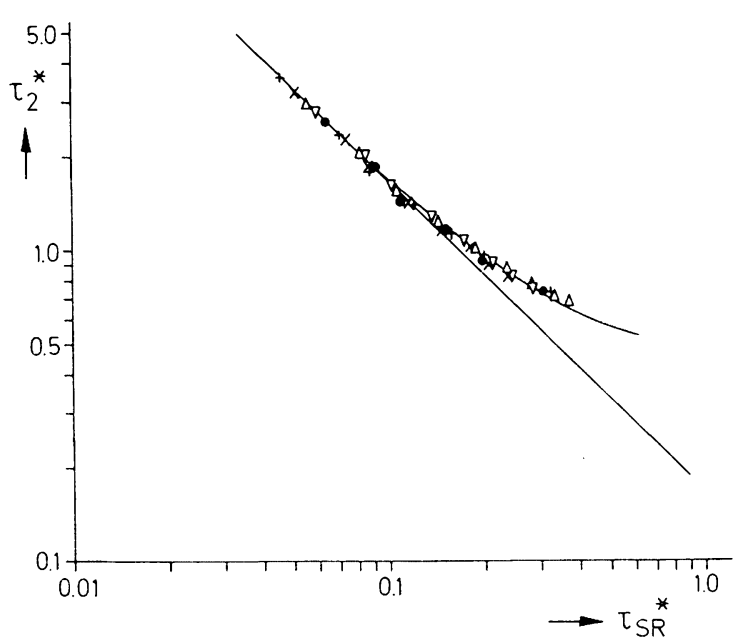

Fig. 13

Reduced orientational correlation times $\tau_{2}^{*}$ versus reduced spinrotational correlation times $\tau_{\mathrm{SR}}^{*}$. Full curve represents the prediction according to the Fokker-Planck-Langevin model. Straight line represents the Hubbard relation $\tau_{2}^{*} \cdot \tau_{S R}^{*}=6^{-1}$ according to the Debye model

tions, however, show features characteristic of high torque liquids $[7,35]$ with torsional oscillations at short times typical for motions in a cage and an exponential long-time-tail signifying Markovian behaviour as a simple consequence of the long range isotropy of the liquid. Integral correlation times are mostly dominated by the Markovian nature of orientational fluctuations. Spin-rotation relaxation relates to fluctuations of the angular velocity and of the orientation of the molecules. Again only integral spin-rotation correlation times $\tau_{\mathrm{SR}}$ of the angular velocity-orientational product correlation function can be determined from an NMR experiment. Also it is only within certain motional models that these bivariate correlation functions have been obtained. Because orientational correlation functions may also be obtained within the realm of these models, a comparison of both $\tau_{2}$ and $\tau_{\mathrm{SR}}$ may provide insight into the state of molecular motions. The Fokker-Planck-Langevin (FPL) model $[27,29,36]$ will be shown to be in reasonable agreement with the experimental results. In this model a single parameter, $\tau_{c,}$, is changed to produce the limits of free rotation and rotational diffusion. The model assumes successive uncorrelated instantaneous collisions with the angular impulse of each collision being so small as to change the angular momentum only infinitesimally. However, random uncorrelated collisions cannot cause a reversal of the angular momentum as is observed in high torque molecular liquids and indeed has been observed in fluoroform also $[6,7,9]$. Hence $\tau_{(1,}$ must be considered a lower limit to the "lifetime" of the angular velocity correlation function. Fig. 13 shows a graph of $\tau_{2}^{*}=\tau_{2} \cdot(k T /\langle I\rangle)^{1 / 2}$ versus $\tau_{S \mathrm{R}}^{*}$. The full curve gives the dependence of $\tau_{2}^{*}\left(\tau_{S R}^{*}\right)$ according to the FPL-model. At the lowest temperatures the reorientational motions are in the rotational diffusion limit $\left(\tau_{S R}^{*}=\tau_{(,)}^{*} \ll \tau_{2}^{*}\right)$, hence the Hubbard relation $\tau_{\omega}^{*} \cdot \tau_{2}^{*}=6^{-1}$ is obeyed. In general reorientational motions in fluoroform deviate less from the rotational diffusion limit than do these motions in methylfluoride [18] investigated in the same range of number densities $Q$ and reduced temperatures $T / T_{\text {c }}$. Finally it is instructive to note that the rough hard sphere model of rotational motions $[37,38]$ gave values of $\tau_{(1)}^{*}$ calculated via the relations

$$
\begin{aligned}
& \frac{1}{\tau_{\omega}^{*}}=\frac{1}{K+1} \frac{1}{\tau_{\mathrm{E}}^{*}} \\
& \frac{1}{\tau_{\mathrm{E}}^{*}}=\frac{8}{3}\left(\frac{\pi \cdot\langle I\rangle}{m \sigma^{2}}\right)^{1 / 2} \cdot \varrho \sigma^{3} \cdot g_{\mathrm{hs}}(\sigma) \\
& \kappa=\frac{\langle I\rangle}{m(\sigma / 2)^{2}}
\end{aligned}
$$

with $\sigma=3.95 \AA$ the hard sphere diameter as obtained from a fit of the rough hard sphere model to the measured selfdiffusion coefficients $D$ and with $g_{\text {hs }}(\sigma)$ calculated via the Carnahan-Starling approximation [39], which are a factor of 2-5 larger than the $\tau_{\mathrm{SR}}^{*}$ deduced from the experimental results in both fluoroform and methylfluoride.

The technical assistance of Mr. R. Knott, E. Treml, G. Wührl and S. Heyn made this work feasible. Financial support by the Deutsche Forschungsgemeinschaft, the Fonds der Chemischen Industrie and the Friedrich Ebert Stiftung is gratefully acknowledged. 


\section{References}

[1] H. S. Gutowsky, I. J. Lawrenson, and K. Shimomura, Phys. Rev. Lett. 6, 349 (1961).

[2] C. S. Johnson, J. S. Waugh, and J. N. Pinkerton, J. Chem. Phys. 35, 1128 (1961).

[3] J. H. Chaffin III and P. S. Hubbard, J. Chem. Phys. 46, 1511 (1967).

[4] J. W. Harrell, Jr., J. Magn. Res. 23, 335 (1976).

[5] R. Clark and M. Bloom, Can. J. Phys. 51, 149 (1973).

[6] A. Gerschel, I. Dimicoli, J. Jaffre, and A. Rion, Mol. Phys. 32, 679 (1976).

[7] A. Gerschel, C. Brot, I. Dimicoli, and A. Rion, Mol. Phys. 33, 527 (1977)

[8] G. Bossis and B. Quentrec, Mol. Phys. 32, 591 (1976).

[9] A. Gerschel, J. Mol. Liquids 25, 51 (1983).

[10] J. De Zwaan, D. W. Hess, and Ch. S. Johnson, Jr., J. Chem. Phys. 63, 422 (1975).

[11] M. L. Martin, G. L. Martin, and J.-J. Delpuech, Practical NMR Spectroscopy, Heyden \& Sons Ltd. 1980.

[12] F. X. Prielmeier, E. W. Lang, and H.-D. Lüdemann, Mol Phys. 52, 1105 (1984).

[13] J. J. V. Tyrrell and K. R. Harris, Diffusion in Liquids, Butterworth \& Co. Ltd. 1984.

[14] B. J. Alder, D. M. Gass, and T. E. Wainwright, J. Chem. Phys. 33, $3813(1970)$

[15] D. Chandler, J. Chem. Phys. 62, 1358 (1975)

[16] R. A. H. Kruse, Ph. D. Thesis, University of Karlsruhe, Karlsruhe, FRG 1981.

[17] P. Tremaine and M. G. Robinson, Can. J. Chem. 51, 1497 (1973).

[18] E. W. Lang, F. X. Prielmeier, H. Radkowitsch, and H.-D. Lüdemann, Ber. Bunsenges. Phys. Chem., submitted for publication 1987.

[19] F. X. Prielmeier and H.-D. Lüdemann, Mol. Phys. 58, 593 (1986).
[20] J. H. Dymond, J. Chem. Soc. Faraday Trans. 2, 68, 1789 (1972).

[21] H. J. Böhm, C. Meissner, and R. Ahlrichs, Mol. Phys. 53, 651 (1984).

[22] H. W. Spieß, Rotation of Molecules and Nuclear Spin Relaxation, in: P. Diehl, E. Fluck, and R. Kosfeld (eds.), NMRBasic Principles and Progress, Vol. 15, Springer-Verlag 1982.

[23] S. G. Kukolich, A. C. Nelson, and D. J. Ruben, J. Mol. Spectrosc. 40, 33 (1971)

[24] L.-P. Hwang and J. H. Freed, J. Chem. Phys. 63, 4017 (1975).

[25] C. A. Sholl, J. Phys. C 14, 447 (1981).

[26] J. F. Harmon, J. Magn. Res. 31, 411 (1978).

[27] R. E. D. McClung, J. Chem. Phys. 73, 2435 (1980).

[28] P. S. Hubbard, Phys. Rev. A 9, 481 (1974).

[29] P. S. Hubbard, Phys. Rev. A 24, 645 (1981).

[30] J. M. H. Reynders, A. W. Ellenbroek, and A. Dymanus, Chem. Phys. Lett. 17, 351 (1972)

[31] T. L. Follett, Ph. D. Thesis, Harvard University, Cambridge, Mass. 1970

[32] R. L. Armstrong and J. A. Courtney, Can. J. Phys. 50, 1262 (1972).

[33] R. Y. Dong and M. Bloom, Can. J. Phys. 48, 793 (1970)

[34] B. C. Sanctuary, Can. J. Phys. 52, 387 (1974).

[35] R. M. Lynden-Bell, in: A. D. Barnes, W. J. Orville-Thomas, and J. Yarwood (eds.), Molecular Liquids - Dynamics and Interactions, p. $501 \mathrm{ff}$., D. Reidel Publishing Company 1983.

[36] G. Lévi, J. P. Marsault, F. Marsault-Hérail, and R. E. D McClung, J. Chem. Phys. 73, 2443 (1980).

[37] D. Chandler, J. Chem. Phys. 60, 3508 (1974).

[38] J. O'Dell and B. J. Berne, J. Chem. Phys. 63, 2376 (1975).

[39] N. F. Carnahan and K. E. Starling, J. Chem. Phys. 51, 635 (1969).

(Eingegangen am 18. Mai 1987)

E 6496

\section{Plancks Strahlungsgesetz und die Quantisierung der Entropie}

\section{Herbert W. Zimmermann}

Institut für Physikalische Chemie der Universität Freiburg i. Br., Albertstraße 21, D-7800 Freiburg, Federal Republic of Germany

\section{Quantum Mechanics / Statistical Mechanics / Thermodynamics}

In order to derive Planck's law of black-body radiation we consider a gas of photons which is in equilibrium with its surroundings at temperature $T$. Instead of the usual energy quanta of the photons $\varepsilon=h v$ we introduce entropy quanta $\sigma=\varepsilon / T$. Now, $\varepsilon$ and $T$ are used from the beginning of the calculations and it is easy to derive Planck's distribution law of the photon gas, avoiding Lagrange's method of undetermined multipliers. Using $\sigma$ instead of $\varepsilon$ we get the entropy-distribution of the black-body radiation which may be transformed by $\varepsilon=h v$ into the usual energy-distribution formula. Conventionally, entropy is a property of an ensemble of particles. But the entropy quantum $\sigma$ is a property of the particle itself which is in thermodynamic equilibrium with its surroundings.

\section{Einleitung}

In den Gleichungen der Wärmestrahlung begegnen sich Quantentheorie und Thermodynamik. Planck [1] ist es bekanntlich als erstem gelungen, unter der Annahme von Energiequanten die Energieverteilung der Hohlraumstrahlung zu berechnen. Im folgenden sollen die Gesetze der Wärmestrahlung nochmals behandelt werden, jedoch unter einem anderen Gesichtspunkt, der vor allem die thermodynamische Seite des Quantenproblems zur Geltung bringen soll.

Dazu untersuchen wir ein Photonengas im Hohlraum eines schwarzen Strahlers, das bei der Temperatur $T$ im Gleichgewicht mit seiner Umgebung steht. Die Photonen werden von den Wänden des Hohlraums reversibel emittiert und absorbiert. Bei Emission eines Photons der Frequenz $v$ wird dem Photonengas die Energie $\varepsilon=h v$ zugeführt. Da das Photon aber auch im Strahlungsgleichgewicht mit seiner Umgebung steht und reversibel isotherm erzeugt wurde, erfährt das Photonengas gleichzeitig den formalen Entropiezuwachs $\sigma=\varepsilon / T$. Die Photonen sind diskrete Teilchen. Ihnen ist dann nicht nur eine diskrete Energie sondern auch Entropie zuzuordnen. In Analogie zu den Energiequanten $\varepsilon=h v$ stehen jetzt die Entropiequanten $\sigma=\varepsilon / T$.

Die Vorstellung von Entropiequanten $\sigma$ ist ungewöhnlich. Sie beinhaltet die Hypothese, daß die Entropie auch eine Eigenschaft einzelner Teilchen ist und nicht nur eines En- 